\title{
Los hiperbóreos: mito y religión ${ }^{1}$
}

\author{
Juan PiQuero Rodríguez \\ Universidad de Alicante \\ jpiquero15@gmail.com
}

Recibido: 25-5-2011

Aceptado: 14-11-2011

\section{RESUMEN}

Los hiperbóreos son un pueblo que vive en un lugar indefinido en el Norte. Pasan el rato entre danzas, música y una vida de ocio. Sólo deben asegurarse de que Apolo recibe las ofrendas que ellos le ofrecen, que llevan hasta la isla de Delos. Apolo es el dios más importante para este pueblo porque, cuando nace en Delos, marcha al norte, con los hiperbóreos. Está claro que Apolo y los hiperbóreos están relacionados entre sí, y esta relación tiene que ver con el sol.

Sabemos que unas ofrendas llegaban a Delos desde los hiperbóreos. Al principio las llevaban unas muchachas, pero pronto los hiperbóreos entregaron sus ofrendas a sus vecinos para que, de pueblo en pueblo, llegaran hasta Delos. Desgraciadamente no sabemos con seguridad en qué consistían esas ofrendas.

Vamos a tratar de explicar aquí por qué Apolo nace en Delos y marcha al país de los hiperbóreos, cuál es la ruta y el contenido de las ofrendas y finalmente, quiénes son esas muchachas y por qué van a Delos.

Palabras clave: hiperbóreos, Apolo, Delos, procesión, ofrendas.

\begin{abstract}
The hyperboreans were people who lived somewhere in the North. They used to spend their time dancing, listening to music and enjoying their spare moments. They only had to make sure Apollo recieved the offerings they gave him, which they took to Delos Island. As Apollo moved to the north, where the hyperboreans lived, he became the most important god for those people. It is clear that Apollo and the hyperboreans are related and also this relation has to do with the sun.

We know that some of the offerings from the hyperboreans got to Delos. In the beginning, the offerings were taken there by some young women, but the hyperboreans soon started giving them to their neighbours, so the offerings arrived at Delos after travelling from town to town. Unfortunately, we don't exactly know what those offerings consisted of.

We'll try to explain here the reason why Apollo was born in Delos and then moved in with the hyperboreans, what the route taken and the content of their offerings were and, finally, who the young women were and why they went to Delos.
\end{abstract}

Key words: hyperboreans, Apollo, Delos, procession, offerings.

${ }^{1}$ Este trabajo forma parte de mi Trabajo de Fin de Máster, Estudios sobre los hiperbóreos, bajo la dirección del profesor Alberto Bernabé. 
Los hiperbóreos aparecen en la literatura griega habitualmente como un pueblo lejano, que habita en el extremo norte ${ }^{2}$ del mundo y cuyos habitantes viven en plena ociosidad, con una felicidad plena entre danzas y música, sólo dedicados al culto a Apolo, un dios que está, como veremos, muy ligado a ellos.

Es bien sabido que los griegos idealizaron los límites del mundo en el que vivían ${ }^{3}$, y que esto mismo hicieron con los escitas o con los etíopes. En cuanto a los hiperbóreos, ya Esquilo se refiere a ellos como un pueblo de «vasta suerte» ${ }^{4}$, pero es Píndaro quien nos da más información. Dice el poeta ${ }^{5}$ : «no está ausente la Musa de sus costumbres. Y por todos lados coros de vírgenes y gritos de liras y estruendos de flautas suenan. Ciñendo sus cabellos con laurel dorado celebran banquetes felizmente. Ni enfermedades ni funesta vejez afectan a su sagrado linaje. Lejos de fatigas y batallas viven huyendo de la intransigente Némesis». Es sin duda en estos versos donde mejor se nos describe la vita hyperborea. Vemos que viven en plena ociosidad, dedicados a labores religiosas que forman parte de la sociedad misma. La música, como en el ideal de paideía griega, forma parte de su vida cotidiana.

Los griegos situaban entre los hiperbóreos todas sus aspiraciones, cuestiones «utópicas» que era imposible que fueran alcanzadas por simples humanos. También Píndaro nos advierte de esto: «ni yendo en navíos ni a pie encontrarías el maravilloso camino a las asambleas de los hiperbóreos $\rangle^{6}$. Los hiperbóreos viven en un status que para los griegos es inalcanzable, de ahí que nosotros podamos definirlo como utopía.

Baste con lo dicho sobre la vita hyperborea, y centrémonos ahora en el campo del mito y la religión.

En los textos que conservamos, Apolo aparece estrechamente ligado al pueblo de los hiperbóreos. En un peán de Alceo se nos relata el mito, que podemos resumir así: Apolo nace en Delos junto con su hermana Ártemis, ambos hijos de Leto, que llega hasta la isla cansada de vagar de un lado a otro sin que nadie le deje dar a luz en sus tierras por temor a la ira de $\mathrm{Hera}^{7}$. Leto alumbra allí a sus hijos, y al momento Zeus manda unos regalos para Apolo: una mitra de oro, una lira y un carro tirado por unos cisnes. Aunque, según parece, Apolo se dirigía hacia Delfos, los cisnes lo llevan hasta el país de los hiperbóreos, y allí administra justicia y se regocija entre fiestas en su honor durante un año. Después que éste transcurre, el dios marcha a Delfos que está esperando ansiosa su llegada, que se produce en verano ${ }^{8}$.

Si pensamos, como creemos, que, para que exista un mito, es precisa una motivación para éste, hemos de preguntarnos dos cosas: por qué Apolo nace precisamente

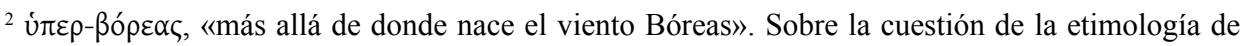
los hiperbóreos se han propuesto varias opciones que son, a nuestro juicio, un poco forzadas. Cf. Harris (1945).

${ }^{3}$ Cf. Romm (1992).

${ }^{4}$ Coéforos, 372-374.

${ }^{5}$ Pítica 10.27-48.

${ }^{6}$ Pítica 10.29-30.

${ }^{7}$ Cf. Himno homérico a Apolo, 45 ss y Calímaco, Himno a Delos, 55 y ss.

${ }^{8}$ Al parecer un peán de Alceo hablaría sobre este viaje, pero es Himerio (48.105-131) quien nos recoge la noticia de manera sumaria. Cf. Page (1979), I (c). 
en Delos y por qué nada más nacer marcha al norte. La cuestión es complicada, pero esperamos poder arrojar algo de luz con los siguientes razonamientos.

La importancia de Delos en la historia de Grecia es indiscutible. En lo mítico, Apolo y Artemis, dos dioses de gran importancia en el panteón griego, nacen allí; en lo político, Atenas hizo de ella la sede de su imperio, al que llamó «ático-délico». Sin embargo, Delos no parece un lugar demasiado adecuado para el alumbramiento de dos dioses tan importantes. Es un islote poco agraciado, un pedregal desolado en medio del mar $^{9}$, una tierra ventosa y batida por las olas.

Calímaco, en su Himno a Delos, nos da algunos datos más en relación con la isla. Nos dice que antiguamente su nombre era Asteria ${ }^{10}$, «pues saltaste — dice — igual que un astro desde el cielo al profundo abismo, huyendo de la unión con Zeus. No habías recibido aún a la resplandeciente Leto. Eras Asteria, tu nombre no era Delos todavía». Cuando Asteria abandona la compañía de los dioses por el acoso de Zeus, se metamorfosea en codorniz, de aquí el nombre de Ortigia que la isla recibe después.

A partir del nacimiento de Apolo la isla comienza a llamarse Delos, «manifiesta, evidente». Según Calímaco, Asteria era una isla errante que vagaba por el Egeo, pero, «cuando ofreciste tu suelo como lugar natal para Apolo, los navegantes te llamaron Delos en lugar de Asteria». Continúa diciendo que los marinos le cambiaron el nombre porque ya no andaba errante e «invisible», sino que ahora era «visible» ${ }^{11}$.

A nuestra manera de ver, el hecho de que el nombre de Asteria esté vinculado, sin lugar a dudas, con «astro», «estrella», y el hecho de que Asteria pase a llamarse Delos, «manifiesta, evidente», en cuanto en ella nace Apolo, responde de alguna manera a que esta isla tiene algún tipo de vinculación con la observación astronómica, y en concreto, con el movimiento del sol ${ }^{12}$.

No es nada raro entonces que precisamente en ese islote yermo nazca precisamente el que fue considerado más tarde (inicialmente el dios del Sol es Helios) por los griegos como el dios del Sol. Aunque últimamente se ha afirmado que el culto a Apolo como deidad solar es más bien tardío ${ }^{13}$, tenemos datos que confirman que existe una identificación entre Apolo-Helios desde, al menos, la época arcaica ${ }^{14}$.

Para dar aún más fuerza a la hipótesis de que Delos tiene alguna relación con el sol, existe un dato incontrovertible ${ }^{15}$. Es Homero en su Odisea ${ }^{16}$ quien nos lo ofrece. Cuando Ulises consigue por fin llegar a Ítaca, habla en un momento dado con su porquero, Eumeo. Le pregunta sobre su lugar de nacimiento, a lo que responde el porquero: «hay

${ }^{9}$ Así aparece ya en las fuentes antiguas. Cf. Himno homérico a Apolo, 51 y ss.

${ }^{10}$ Himno a Delos, 37 y ss. También Píndaro, fr. 52e, 42. Maehler.

${ }^{11}$ Himno a Delos, 41 y ss.

${ }^{12} \mathrm{Cf}$. también Himno homérico a Apolo, 14 y ss. donde se dice que Ártemis nace en Ortigia, pero Apolo lo hace ya en Delos. Esto ha sido considerado un simple juego erudito por algunos estudiosos, pero a nuestro juicio, el asunto podría tener una motivación más profunda.

${ }^{13}$ Rose (1974:134).

${ }^{14}$ Cf. Esquilo, Suplicantes, 212-214; Bassarai, Radt (1985:138); Lucas (2008: 224 y ss); Burkert (2007: 201, n. 55; 304).

${ }^{15}$ Es en Souvirón (2008: 340 y ss) donde por primera vez aparece planteada esta cuestión. Nuestra exposición es en una buena parte deudora de lo que allí se dice.

1615.402 y ss. 
una isla llamada Siria, no sé si la conoces de oídas, por encima de Ortigia, donde da la

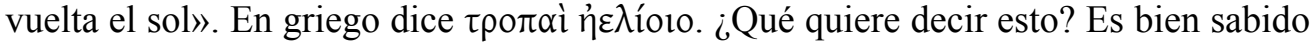
que en griego la palabra $\tau \rho \circ \pi \eta ́$ significa «vuelta», y no pocos autores utilizan el término para referirse al solsticio ${ }^{17}$.

El solsticio es «la parada del sol» en su viaje norte-sur. En un lugar concreto el sol «se para» y «da la vuelta» de nuevo en dirección contraria ${ }^{18}$. Este fenómeno es comprobable por parte de cualquier individuo a partir de la mera observación, y no creemos que se necesitaran técnicas de observación astronómica demasiado avanzadas para que alguien se percatara de este suceso ${ }^{19}$.

Esta «parada del sol» y su viaje de nuevo hacia el norte, creemos, sería una buena motivación para el mito. Apolo, el sol, nace en Delos porque en algún momento a lo largo del año parece que «se para» sobre esta isla, no avanza más hacia el sur. Después, poco a poco, marcha hacia el norte, hacia un lugar indeterminado donde, de la misma forma, «se para», «da la vuelta» y repite de nuevo su viaje hacia el sur. Ese lugar indeterminado al norte sería la patria de los hiperbóreos ${ }^{20}$.

Yendo un poco más allá, pensamos que también los montes Ripeos pueden tener que ver con este viaje del sol. Sabemos que en la Antigüedad existía la creencia de que los vientos tenían que ver con el movimiento norte-sur/ sur-norte del sol, y, más concretamente, el viento del norte ${ }^{21}$. La etimología de Ripeos tiene que ver con pín $\tau \omega$, que viene a significar «lanzar». Con el Bóreas «se lanza» también el sol en su viaje hacia el $\operatorname{sur}^{22}$.

En definitiva, creemos que el culto a Apolo Hiperbóreo tiene que ver con el viaje norte-sur / sur-norte del sol y la posición de los solsticios. Pensamos que este es un razonamiento que sirve bien para explicar por qué los griegos creían que en un lugar indeterminado del norte había unos individuos que compartían con ellos un dios común: el sol.

Esto en lo que atañe al mito sobre Apolo; pasaremos ahora a ver los datos en torno a la procesión y las ofrendas.

\section{LAS OFRENDAS Y LAS MUCHACHAS HIPERBÓREAS}

Este asunto ha sido de gran interés para los estudiosos, y aunque se han propuesto todo tipo de hipótesis, nos detendremos a analizar con un poco de tranquilidad este tema.

${ }^{17}$ Hesíodo, Trabajos, 479, 564, 663; Heródoto 2.19; Platón, Leyes, 767c; Aristóteles, Sobre el cielo, $296 b$.

${ }^{18}$ Cuando decimos que el sol «se para» o «da la vuelta», estamos hablando de una percepción visual desde la tierra. Huelga decir que los que nos movemos somos nosotros.

${ }^{19}$ Cf. Dicks (1966) y la acertada crítica de Kahn (1970: 111 y ss).

${ }^{20}$ Que los griegos creían que Apolo tenía que ver con un viaje del sol norte- sur explica que existan templos dedicados a Apolo como el de Bassas o el de Apolo Hylates en Chipre cuya orientación es nortesur en lugar de este- oeste.

${ }^{21}$ Heródoto 2.24 y notas en Scharder (2006: 304). Cf. también Lucrecio, De rerum natrura, 5.637-649.

${ }^{22}$ Hipócrates, Sobre los aires, aguas y lugares, 19. Cf. también Desautels (1971). 
Heródoto es el primero que nos habla sobre una procesión que, anualmente, llega desde los hiperbóreos hasta Delos con unas misteriosas ofrendas ${ }^{23}$. Comienza diciendo que sólo «acaso los isedones» dan alguna información sobre los hiperbóreos, y que también Homero en sus Epígonos ${ }^{24}$ y Hesíodo ${ }^{25}$ dicen algo sobre ellos; «pero quienes dan muchísimas más informaciones sobre ellos son los delios». Continúa Heródoto diciendo que los delios afirman que hasta allí llegan unas ofrendas embaladas en pajas de trigo que van pasando de mano en mano desde los hiperbóreos. De ellos pasan a los escitas, y de éstos, «van siendo recibidas por los pueblos vecinos, que las transportan hacia occidente, hasta las muy lejanas costas del Adriático». Desde aquí van al sur, hasta el santuario de Dodona; y de allí al golfo Melieo y Eubea, donde llegan a Caristo, al sur de la isla; de allí a Tenos y son sus habitantes quienes las llevan finalmente a Delos.

Continúa Heródoto diciendo que «la primera vez dicen que los hiperbóreos enviaron a dos muchachas para que trajeran las ofrendas sagradas, los delios las llaman Hipéroca y Laódice». Con ellas, para su protección, mandaron los hiperbóreos a cinco hombres de su ciudad, los llamados Perfereos. Ellas vinieron a Delos para entregar a Ilitía ${ }^{26}$ un tributo por acudir finalmente a ayudar a Leto en el parto.

Antes que Hipéroca y Laódice llegaron, según Heródoto, otras dos muchachas «en compañía de las mismas diosas $»^{27}$, Arge y Opis.

También Calímaco ${ }^{28}$ trata el tema de las ofrendas, aunque de un modo mucho menos sistemático. Con todo, nos da algún dato nuevo. Dice de Delos: «siempre recibes ofrendas de los primeros frutos como diezmo». Refiriéndose más concretamente a los hiperbóreos dice «los que llevan los primeros la caña de trigo y las sagradas gavillas de espigas»». Más adelante hablaremos sobre el delicado tema de las ofrendas y las hipótesis al respecto.

En cuanto al itinerario de las mismas, ofrece pocos datos nuevos. Dice «que vienen desde muy lejos» y coincide con Heródoto en que los primeros griegos en recibirlas son los de Dodona. Después pasan a la ciudad de Sagrada ${ }^{29}$ y «a los montes de la tierra Mélide», en Tesalia. De allí «a la fértil llanura de Lelantia de los abantes», es decir, Eubea; y desde aquí a Delos. Vemos que la descripción es más somera que en Heródoto, pero hay que recordar que no es el propósito del poeta dar un itinerario detallado, sino, simplemente, perfilarlo para dejar patente su erudición ${ }^{30}$.

${ }^{23} 4.32$ y ss.

${ }^{24}$ Obra perdida perteneciente al ciclo épico que, en los autores más antiguos, se atribuía también a Homero.

${ }^{25}$ Fr.150, Merkelbach-West (1990), desgraciadamente en un estado muy fragmentario.

${ }^{26}$ Diosa de los partos que, por temor a Hera, tardó un tiempo en acudir a Delos para ayudar a Leto. Cf. Himno homérico a Apolo, 92 y ss.

${ }^{27}$ Sigo la lectura de Legrand (1960). Los manuscritos leen «dioses». Creemos que las muchachas formaban parte del cortejo de diosas que llegaron a Delos para acompañar a Leto en su alumbramiento. Cf. Himno homérico a Apolo, 93 y ss.

${ }^{28}$ Himno a Delos, 276 y ss.

${ }^{29}$ O Iro, según la hipótesis de Pfeiffer (1965). Los manuscritos leen ícó́v, «la ciudad sagrada». Probablemente el texto se refiere a Ambracia, donde estaba el Hierón óros.

${ }^{30}$ Según Mineur (1984) estas ofrendas de las que habla Calímaco serían ya un eco lejano de las de los hiperbóreos. El tema se estaría aprovechando para reflejar los regalos que, desde todas las partes del mundo, llegaban a Alejandría con motivo del cumpleaños del rey. 
Un último dato aporta Calímaco frente a Heródoto. Dice que las primeras en portar las ofrendas hasta Delos fueron Upis, Loxo y Hecaerge. Nos encontramos con una tal Loxo y otra Hecaerge que no están en el relato herodoteo, aunque está claro que son feminizaciones de los epítetos de Apolo Hecaergos y Loxias; Upis parece otra lectura de Opis.

El viajero Pausanias también nos ofrece un relato sobre las ofrendas de los hiperbóreos $^{31}$. Este aventurero nos da una ruta distinta a la que nos ofrece Heródoto. Dice que las ofrendas pasan de mano en mano desde los hiperbóreos a los arimaspos y, de éstos, a los isedones. Ellos se las dan a los escitas para que las lleven a Sinope. Tenemos aquí una reelaboración a partir de lo que cuenta Heródoto sobre los Arimaspea de Aristeas de Proconeso ${ }^{32}$, pero el de Halicarnaso no nos ofrece esta parte de la ruta. Simplemente dice que llegan a los escitas y de ahí «van siendo recibidas por todos los pueblos vecinos, que las transportan hacia occidente, hasta las muy lejanas costas del Adriático»».

Cuenta Pausanias que las ofrendas llegan a Sinope ${ }^{33}$, y que de allí, los griegos las llevan hasta Prasias ${ }^{34}$, donde había un templo de Apolo. De aquí pasan a Delos.

Veamos con un poco de detenimiento estos textos.

No hay duda de que Heródoto consigue la información sobre esta procesión desde las tierras hiperbóreas a partir de lo que le cuentan en Delos. Dice que hasta allí llegan «unas ofrendas sagradas embaladas en paja de trigo» ${ }^{35}$. No dice más, no podemos saber en qué consistían. Calímaco por su parte dice en su Himno a Delos ${ }^{36}$ «siempre recibes ofrendas de los primeros frutos como diezmo», y más adelante que los hiperbóreos son «los que llevan los primeros la caña de trigo y las sagradas gavillas de espigas». Tenemos aquí algún dato más. Finalmente Pausanias dice que «las primicias estaban escondidas entre pajas de trigo, y nadie pudo conocerlas $\rangle^{37}$. Hasta aquí lo que dicen los textos.

En cuanto al contenido de las ofrendas, ha habido propuestas para todos los gustos: unos han pensado que consistían en huevos de cisne ${ }^{38}$, otros en miel de «las abejas hiperbóreas ${ }^{39}$, otros en primicias de sacrificios ${ }^{40}$; sin embargo, las hipótesis mejor fundadas son las que plantean que las ofrendas son ámbar o, simplemente, espigas de trigo.

${ }^{31}$ Descripción de Grecia, 1.31.

324.13.

${ }^{33}$ Una colonia de Mileto al sur del mar Negro, en la costa norte de la actual Turquía. Probablemente fue fundada a mediados del s.vII a.C. Cf. Drews (1976: 25).

${ }^{34} \mathrm{Al}$ este del Ática, frente a Eubea.

354.33 .

${ }^{36} 279-280$.

${ }^{37} 1.31 .2$.

${ }^{38}$ Es clara la vinculación de estas aves con Apolo. Cf. Calímaco, Himno a Delos, 250 y ss., Eliano, Historia de los animales, 2. 32 y, en Page (1979), I (c).

${ }^{39}$ Cf. Pausanias, 10.5.10. Creemos que de aquí saldría esta explicación.

${ }^{40}$ A partir de la interpretación tardía de hierá por «víctimas». 
Nos vamos a detener en estas dos últimas ${ }^{41}$. Es innegable que, al menos desde la Edad de Bronce, ha habido comercio con el ámbar desde la zona de Jutlandia y Prusia oriental. Es también perfectamente constatable el hecho de que, desde muy temprano, encontramos ámbar en tumbas de época micénica tanto en el continente como en las islas, al menos en $\mathrm{Creta}^{42}$, pero también en lugares tan alejados como Egipto. El ámbar sólo puede proceder del norte de Europa, y podemos seguir las rutas por donde llegaba a lugares tan dispares ${ }^{43}$. Una de estas rutas venía desde Prusia oriental ${ }^{44} \mathrm{y}$, camino al sur, llegaba hasta el Istro, por lo que no sería raro que el ámbar entrara por esta vía fluvial a Grecia, habida cuenta de las relaciones comerciales por el Istro desde la colonia de Istria, en el mar Negro. Estudiosos modernos han planteado algunas opiniones interesantes. Harris ${ }^{45}$ ofrece como posibilidad una «vía sagrada» que vendría desde el lejano norte hasta Grecia pasando por diferentes escalas, que, según él, guardan una estrecha relación con Apolo a partir de una serie de etimologías que él propone, pero que creemos demasiado forzadas. También Seltman ${ }^{46}$ plantea que las ofrendas consistirían en ámbar, y que la colonia de Barbosi ${ }^{47}$, fundada a mediados del s.VI a.C., serviría de nexo entre los que trajeran el ámbar por el Istro y los comerciantes de Istria. Objeciones a que pudiera tratarse de ámbar son que, precisamente, en las tumbas de las muchachas hiperbóreas en Delos, no ha aparecido ni un solo fragmento ${ }^{48}$ y que no hay referencia alguna al ámbar en los textos que conservamos.

Es Tréheux ${ }^{49}$ quien plantea la hipótesis que parece más plausible, atendiendo a los datos que tenemos. Dice, no sin razón, que las ofrendas tenían que consistir en algo que no se estropeara con el paso del tiempo que transcurriría desde su salida de los lejanos hiperbóreos hasta su llegada a Delos. A partir de esto y de que Calímaco ${ }^{50}$ dice textualmente «siempre recibes ofrendas de los primeros frutos como diezmo», concluye que sólo puede tratarse de espigas de trigo. Así, las espigas de las que nos hablan todos los textos no ocultarían nada, sino que simplemente serían estas mismas las misteriosas ofrendas. Ayuda a esta hipótesis el que, según sabemos, el altar de Apolo Genétor en Delos nunca sirvió para el sacrificio de sangre ${ }^{51}$, por lo que estas primicias de espigas de trigo bien podían ser ofrecidas aquí ${ }^{52}$. A falta de más datos, esta opción es la que nos parece más plausible.

Pasemos a ver qué podemos sacar más o menos en claro de los datos que ofrecen los textos. A nuestra manera de ver, el testimonio de Heródoto es el más importan-

${ }^{41}$ Para un estudio pormenorizado de todas las hipótesis, remito a Tréheux (1953: 764 y ss).

${ }^{42}$ Picard (1927).

${ }^{43}$ Cf. el ya clásico trabajo de Navarro (1925) para hacerse una idea de la magnitud de este comercio.

${ }^{44}$ Muy probablemente desde la zona del golfo de Gdansk.

${ }^{45}$ Harris (1925).

${ }^{46}$ Seltman (1928).

${ }^{47}$ En la actual Rumanía, a orillas del Danubio.

${ }^{48}$ Aunque, evidentemente, puede haber sido robado por cualquiera de los piratas que atracara en la isla desde muy temprano. No es nada raro que el ladrón robe una tumba pero la deje intacta, seguramente, por la creencia popular en que destruir tumbas trae mala suerte.

${ }^{49}$ Tréheux (1953: 765 y ss).

${ }^{50}$ Himno a Delos, 277.

${ }^{51}$ Burkert (2007: 95).

${ }^{52}$ Para este tipo de ofrendas de primicias véase Burkert (2007: 92 y ss). 
te por varias razones: porque sabemos que su fuente son precisamente los delios ${ }^{53}$, porque su fin es transmitir este episodio, como cualquier otro, con todos los detalles posibles, y porque además es el más antiguo. Creemos que dice algo especialmente importante para poder hacernos una idea sobre el lugar de origen de las ofrendas: de pueblo en pueblo «las transportan hacia occidente, a las muy lejanas costas del Adriático, y de aquí son enviadas hacia el sur». Partiendo de este dato, creemos que tenemos que situarnos en la zona del mar Negro. Además, el hecho de que Pausanias nos dé una secuencia, entre mítica y real ${ }^{54}$, de los pueblos vecinos de los hiperbóreos, nos lleva también a situarnos en esta zona.

Lo más difícil, sin duda, es establecer el lugar de donde esas ofrendas parten a Delos; en su viaje por Grecia tenemos algunos puntos bastante claros. Uno de ellos es su paso por Dodona, tanto Heródoto ${ }^{55}$ como Calímaco $^{56}$ así lo afirman. Sabemos que van hacia el golfo Melieo, a la isla de Eubea, pero Calímaco nos da algún dato más. Dice que «llegan a la ciudad Sagrada y a las montañosas tierras de Mélide» ${ }^{57}$. Cabe plantearse entonces cuál es esta ciudad Sagrada. Algunos estudiosos han visto en este dato una referencia a Antela, en Tesalia ${ }^{58}$, donde existía un santuario de Deméter de gran importancia, por donde pasaría la ruta sagrada de las ofrendas. Mucho más plausible parece la hipótesis de Biancucci ${ }^{59}$. Según su razonamiento, esta ciudad sería Ambracia, donde estaba el Hierón óros, probablemente el punto preciso por el que pasarían las ofrendas.

Una vez pasan Tesalia y llegan a Eubea, dice Heródoto que llegan hasta Caristo, al sur de la isla. De allí van a Tenos y son sus ciudadanos quienes las hacen llegar finalmente a Delos ${ }^{60}$. Un dato curioso que nos ofrece Heródoto es que las ofrendas «pasan de largo Andros», quizá porque la divinidad principal de esta isla era Dioniso ${ }^{61}$.

El itinerario de Pausanias es radicalmente distinto a éste. Dice que las ofrendas son llevadas por los escitas a Sinope, al sur del mar Negro, y de aquí «fueron llevadas a través de los griegos» hasta Prasias, en el Ática. De aquí son los atenienses los encargados de llevarlas a Delos.

Existen, creemos, al menos dos razones para que la ruta de las ofrendas haya cambiado su itinerario en dos momentos distintos cronológicamente: a) la importancia de Atenas, muy especialmente en relación con Delos, de manera que probablemente los atenienses querían también formar parte de esa tradición de las ofrendas de los hiperbóreos, y, cuando tomaron el control sobre la isla, se cumplió su voluntad; b) la invasión de los Balcanes por parte de los celtas, que haría que estas ofrendas desviaran su camino hacia oriente ${ }^{62}$. A nuestra manera de ver, aunque esta segunda hipótesis es

\footnotetext{
534.33 .

${ }^{54}$ Heródoto, 4. 21-27.

554.33 .

${ }^{56}$ Himno a Delos, 286 y ss; fr. 186 Pfeiffer (1965).

${ }^{57}$ Himno a Delos, 287 y ss.

${ }^{58}$ Picard (1946).

${ }^{59}$ Biancucci (1973).

${ }^{60}$ Según Calímaco son los eubeos quienes las llevan directamente a Delos. Cf. Himno a Delos, 289 y ss.

${ }^{61}$ Como bien ilustra el cuadro de Tiziano Fiesta de Dioniso en Andros.

${ }^{62}$ Cf. Biancucci (1973: 217 y ss).
} 
innegable, creemos que más bien habría ocurrido por la influencia de Atenas, cronológicamente anterior.

De lo expuesto aquí podemos concluir que las ofrendas parten, como se sabe, de un lugar al norte de Grecia. Ese lugar ha venido condicionado siempre por el contenido de las ofrendas, así, quien piensa, por ejemplo, que es ámbar, las hace venir desde la zona de Jutlandia y el mar Báltico. No tenemos al respecto ningún dato concluyente, sólo sabemos que en un primer momento van hacia occidente, al Adriático. Es bastante probable que las ofrendas partan desde alguna colonia del mar Negro, porque sabemos además que en la gran mayoría era precisamente Apolo la divinidad principal ${ }^{63}$.

Si consistieran en ámbar podrían partir al menos de Istria, donde llegaría este producto, transportado desde el muy lejano Báltico, a través del Istro. Nosotros pensamos que muy plausiblemente estas ofrendas puedan consistir simplemente en trigo ${ }^{64}, \mathrm{y}$ precisamente la zona del mar Negro ha sido desde siempre el granero de Grecia, por lo que no sería nada raro que vinieran desde allí.

Conviene poner en relación el mito con la realidad de las ofrendas, y vamos a intentarlo. A nuestra manera de ver, en primer lugar existiría una creencia en un pueblo del lejano norte, que vive una vida feliz ajena a los problemas del mundo real: los hiperbóreos. Su extraña relación con Delos estaría basada en la posición del sol en los solsticios, de manera que los delios pensarían que existía algún tipo de vínculo con ese lugar, desconocido, en donde el sol «para»y «da la vuelta», como lo hace sobre su isla. Por tanto, Apolo, el sol, tendría culto en los dos lugares más lejanos adonde se creería que llega en su viaje norte-sur. Por otra parte hay unas ofrendas, que desde algún lugar del norte, llegan a Delos. A juicio de los delios, esas ofrendas sólo pueden venir desde ese lugar al norte donde Apolo recibe un culto semejante al que existe en su isla: los hiperbóreos.

Centrémonos ahora en las muchachas. Por lo que nos cuenta Heródoto ${ }^{65}$, a Delos llegaron cuatro muchachas en grupos de dos. Las primeras fueron Opis y Arge, las segundas Hipéroca y Laódice. Todas estas muchachas están enterradas en la isla de Delos, y reciben culto por parte de sus gentes.

Al contrario de la narración herodotea, expondremos el tema de un modo cronológico; por esto comenzaremos hablando de las primeras que llegaron: Opis y Arge. Heródoto dice que estas muchachas llegan a la isla «con las propias diosas» ${ }^{66}$, probablemente haciendo referencia a esas que acudieron a Delos para acompañar a Leto en el parto ${ }^{67}$. Hemos de detenernos un momento para tratar de ver qué se esconde tras estos nombres.

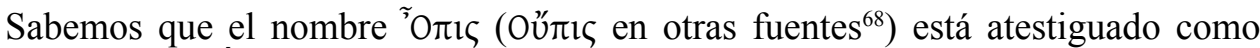
mero epíteto de Ártemis ${ }^{69}$; es también una ninfa que acompaña a la diosa en su sé-

\footnotetext{
${ }^{63}$ Seltman (1928: 157).

${ }^{64}$ Cf. para más datos Tréheux (1953).

${ }^{65} 4.33 .3$ y ss.

${ }^{66} \mathrm{Cf}$. nota 26.

${ }^{67}$ Himno homérico a Apolo, 92 y ss.

${ }^{68}$ Calímaco, Himno a Ártemis, 204.

${ }^{69}$ Virgilio, Eneida, 11. 532 y ss; Servio, Comentario a la Eneida, 11.532.
} 
quito $^{70}$. Para el nombre de Arge la cuestión es más complicada, y no tenemos nada que confirme realmente que es otro epíteto de Ártemis, como se ha sugerido algunas veces $^{71}$. Tenemos otro nombre que algunas veces ha sido equiparado al de Arge: He-

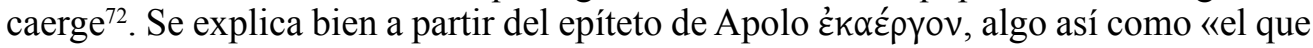
acierta de lejos»», haciendo referencia a su habilidad de arquero ${ }^{73}$. Este epíteto se aplica también a Ártemis en el mismo sentido ${ }^{74}$.

Es realmente complicado dar una explicación satisfactoria de quiénes son realmente Opis y Arge/Hecaerge. En cualquier caso forman parte del mismo cortejo en el que otras diosas llegaron a Delos, y alguna fuente afirma que ambas fueron algo así como las «doncellas» que cuidaron a Apolo y Ártemis en la niñez ${ }^{75}$. No sería raro entonces que, según el mito, hubieran vivido en Delos y muerto allí; en la isla se encuentra su tumba y se hace una fiesta en su honor.

El propio Heródoto ${ }^{76}$ nos da la situación exacta de la $\theta \eta ́ k \eta$ de las muchachas: «detrás del Artemision, orientada hacia el este, muy cerca del albergue de los de Ceos»». La arqueología ha demostrado que efectivamente existe en ese lugar una tumba que contiene vasos del periodo Heládico Reciente I-III ${ }^{77}$, y, evidentemente, se ha identificado con la tumba de Opis y Arge ${ }^{78}$. Probablemente esta tumba ha servido como lugar de puesta en escena del mito de las muchachas hiperbóreas, como ocurría, por ejemplo, con «las tumbas de los Siete» en Eleusis, de época heládica ${ }^{79}$.

Hemos dicho que había unas fiestas en honor a las muchachas. Dice Heródoto ${ }^{80}$ que las mujeres hacen colectas invocándolas en un himno que había compuesto «el licio Olén» y que isleños y jonios acuden a estas fiestas. Una vez hacen los sacrificios, queman los muslos en el altar y derraman las cenizas sobre la tumba. Ya en el Himno homérico a Apolo $^{81}$ vemos que existía una fiesta para celebrar a Apolo (quizá su nacimiento), donde acuden también «los jonios de arrastradizas túnicas con sus hijos y sus castas esposas». No sería nada raro que en esta gran fiesta pan-jónica se rindiera también tributo a esas muchachas, Opis y Arge, que llegaron para asistir al alumbramiento de Apolo, y que, quizá, fueran nodrizas del dios y de Ártemis.

${ }^{70}$ Nýmphe en un sentido amplio, no sólo como divinidad agreste, de arroyos y flores, sino como "novia" o "muchacha virgen".

${ }^{71}$ Schrader (2006: 312, nota 145). Quizá tenga alguna relación con ỏ $\rho \gamma \eta ́$ ৎ, que significa «brillante».

${ }^{72}$ Pausanias 1.43.4 y Servio, Comentario a la Eneida, 11.532 para su equiparación. La primera fuente donde Hecaerge aparece citada es en Calímaco, Himno a Delos, 292. Según Sale (1961: 86), Hecaerge prevalece sobre Arge porque "suena mejor", aunque, evidentemente, es perfectamente discutible.

${ }^{73}$ Cf. Heráclito, Alegorías de Homero, 7.8.

${ }^{74}$ Aristófanes, Tesmoforiantes, 972; Clememente de Alejandría, Stromata, 5.8.

${ }^{75}$ Servio, Comentario a la Eneida, 11.532.

76 4.35.4.

${ }^{77}$ Aunque, al parecer, la tumba es de época micénica y estos vasos serían de un depósito de fundación del templo.

${ }^{78}$ Courby (1912: 63 y ss.).

${ }^{79}$ Cf. Burkert (2007: 275).

${ }^{80} 4.35$.

${ }^{81} 146$ y ss. 
Según el testimonio de Tucídides ${ }^{82}$ estas fiestas debieron durar bastante tiempo todavía en época antigua, pero acabaron por dejar de celebrarse. Son los atenienses quienes, después de la purificación de Delos ${ }^{83}$, instituyen de nuevo este festival: las Delias, que se celebran cada cuatro años. Dice Tucídides que consistía más o menos en lo mismo, con coros, danzas, música, pugilato, pero ahora con carreras de carros, «cosa que antes no existía».

Es bastante probable que sea en este contexto de las Delias donde hemos de situar la llegada de las ofrendas a Delos. Conservamos algunas inscripciones ${ }^{84}$ donde se habla de ícpó y ỏ゙ $\alpha \rho \chi \alpha i ́$, precisamente lo que nos dicen los textos de Heródoto, Calímaco y Pausanias que llegaba hasta la isla. Son del s. IV y III a.C., y según creen algunos estudiosos, podría ser que llegaran a Delos a comienzos del verano, en junio, precisamente cuando el sol estaría prácticamente en su solsticio, sobre la isla ${ }^{85}$. Por esto es innegable que en el contexto de una fiesta, de las Delias, llegan hasta la isla ofrendas en forma de primicias ${ }^{86}$. Es una fecha un poco tardía en relación con los datos de Heródoto, sin embargo no hay por qué dudar de que los atenienses, al igual que recuperaron esta fiesta para disfrute de los jonios, volvieran a imponer aquellas tradiciones antiguas que se efectuaban en ese contexto.

Nos queda hablar sobre las otras dos muchachas hiperbóreas: Hipéroca y Laódice. Heródoto ${ }^{87}$ dice que estas muchachas fueron las que trajeron las ofrendas la primera vez, y que venían acompañadas por unos legados llamados Perfereos. Sin embargo, ni las muchachas ni los legados volvían a su tierra, de manera que, los hiperbóreos decidieron enviar las ofrendas de pueblo en pueblo hasta Delos, como más arriba hemos visto. Cuenta también Heródoto que, al igual que sus paisanas Opis y Arge, estaban enterradas en la isla y recibían algún tipo de culto.

Según nos dice el historiador, la tumba de estas muchachas está «yendo hacia el Artemision, está fuera a mano izquierda, y ha crecido allí un olivo». Igual que en la anterior tumba, la arqueología moderna ha descubierto una tumba en el enclave que nos da Heródoto. Data del periodo Micénico Medio I-II, y, al parecer, fue objeto de culto hasta el Micénico Reciente II. Para más datos, se encontraron husos en la tumba $^{88}$, lo que confirma esto que nos cuenta Heródoto: las mozas de Delos, antes de su boda, se cortan un rizo del pelo y, enrollándolo en un huso, lo depositan sobre la tumba de Hipéroca y Laódice ${ }^{89}$; los mozos, se cortan un mechón de su cabello y, enrollándolo con hierba, lo depositan sobre la tumba de los Perfereos $^{90}$.

823.104 y ss.

83 425-424 a.C.

${ }^{84} I G \mathrm{II}^{2}, 1636, \mathrm{~A}, 1.8 ; I D, 98,100$ y 104(3). Cf. Durrbach (1911), Courby (1938) y Tréheux (1953) p. 762 .

${ }^{85}$ Para más datos remito al interesantísimo estudio de Tréheux (1953).

${ }^{86}$ Muy probablemente acompañadas de música. Cf. Pseudo-Plutarco, Sobre la música, 1136b.

${ }^{87}$ 4.33.3.

${ }^{88}$ Cf. Picard- Replat (1924: 247 y ss).

${ }^{89}$ Esta costumbre no es rara en Grecia, pues, según Pausanias (1.43.4), las muchachas megarenses también antes de la boda «ofrecen parte de sus cabellos» a la tumba de Ifínoe, esposa de Alcátoo, hijo de Pélope.

904.34 
La razón de este ritual no está demasiado clara, pero parece que esta ofrenda forma parte de un «ritual de paso», por el que tienen que pasar obligatoriamente tanto ellas como ellos.

Nos queda un tema un poco delicado: ¿para quién son esas ofrendas? El propio Heródoto nos dice que Hipéroca y Laódice llegaron a la isla «para satisfacer a Ilitía el tributo que se había fijado por el rápido parto», con que, en principio parece que estas ofrendas iban destinadas a Ilitía. Sabemos que Ilitía es una diosa importante en época minoico-micénica: es la diosa de los partos. Ya en la Odisea se nombra una «cueva de Ilitía», junto a Amniso, cerca de Cnosso, que, por cierto, ha sido descubierta por los arqueólogos ${ }^{91}$. También está en las tablillas micénicas en Lineal B, donde se la nombra como e-re-u-ti-ja, en el contexto de una ofrenda en Amniso ${ }^{92}$. Finalmente su culto se asocia al de Ártemis, que pasa a convertirse también en diosa de los partos ${ }^{93}$. Su nombre significa algo así como «la que llega»; cuando por fin llega, la mujer da a luz, igual que en el caso de Leto que ya hemos comentado.

A la luz de estos datos, no sería raro que los hiperbóreos hubieran mandado en un primer momento estas ofrendas a Ilitía por haber hecho del parto algo rápido, como nos dice Heródoto ${ }^{94}$. Sin embargo, pronto Apolo se haría con el control de Delos, y de la misma forma que expulsa a Temis o mata a Pitón (divinidades femeninas más arcaicas), procede con Ilitía: las ofrendas en su honor pasan a serlo de Apolo. La divinidad masculina se impone sobre la femenina, cosa que ocurre habitualmente en la religión griega a partir de época micénica ${ }^{95}$.

Antes de seguir, hemos de hacer hincapié en que Calímaco ${ }^{96}$ cita también a las muchachas hiperbóreas, aunque diverge de Heródoto en sus nombres: Upis, Loxo y Hecaerge. Sobre Upis y Hecarge ya hemos hablado más arriba; en cuanto a Loxo, qui-

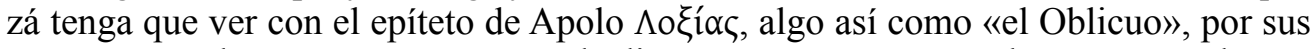
oscuros oráculos, que no son para nada directos. Parece que aquí hay una mezcla con otra tradición que aportaría nombres nuevos, aunque el hecho de que en lo referente a las tumbas haya en Delos precisamente lo que nos cuenta Heródoto, y que él lo toma de los delios, nos lleva a pensar que es más válido su relato que el de Calímaco.

Algunos estudiosos han preferido agrupar a las cuatro muchachas como si su llegada a Delos hubiera sido por un mismo motivo: el de traer ofrendas ${ }^{97}$.

Nosotros, sin embargo, hemos preferido diferenciar dos funciones y dos cultos: el primero a Opis y Arge, algo así como unas heroínas, o diosas arcaicas de poca importancia ${ }^{98}$ que llegan a Delos desde los hiperbóreos en compañía de otras diosas que acuden a acompañar a Leto en su parto. Probablemente fueron además las nodrizas

${ }^{91}$ Burkert (2007: 38).

${ }^{92} \mathrm{KN} \mathrm{Gg} 705$.

${ }^{93}$ No deja de ser sorprendente que la diosa de los partos sea asimilada con la diosa virgen por excelencia, Ártemis. A nuestro juicio, la cosa no está tan clara, pero no es este el lugar para argumentar nuestra opinión. Cf. Souvirón (2011: 158 y ss).

${ }^{94}$ Cf. también Pausanias, 1.18.5.

${ }^{95}$ Cf. Souvirón (2006: 118 y ss).

${ }^{96}$ Himno a Delos, 291 y ss.

${ }^{97}$ Picard (1946) y (1947); Nilsson (1968: 612 y ss).

${ }_{98}$ Ya hemos dicho que Opis aparece pronto como simple epíteto de Ártemis. 
de Apolo y Ártemis ${ }^{99}$ y murieron en Delos, lo que lleva a que su tumba, como otras muchas tumbas de época micénica, fuera objeto de culto para los jonios. Según algunos estudiosos ${ }^{100}$ afirman, Opis y Arge tienen algún tipo de relación con divinidades agrarias. Creemos que esto parte de un error: que estas dos, como las otras, también traen algún tipo de ofrendas, pero no es así. Además, difícilmente alguna divinidad agraria puede tener relación con Ártemis, que, como bien dice Burkert, «es la diosa del campo abierto, fuera de ciudades y pueblos, y fuera de los campos cultivados por acción del hombre» ${ }^{101}$.

El mito aprovecha la realidad de unas tumbas micénicas ${ }^{102}$ como escenario para un ritual que, probablemente, estaría dentro de unas fiestas pan-jónicas ${ }^{103}$, que más tarde recibirían el nombre de Delias.

Un culto distinto es el que existe para Hipéroca, Laódice y los Perfereos ${ }^{104}$. Es un ritual de paso al que se someten mozas y mozos dejando respectivamente un mechón de sus cabellos sobre las tumbas de Hipéroca y Laódice o los Perfereos. Al igual que con la tumba de Opis y Arge, una tumba micénica de gran antigüedad, es objeto de culto para los delios. Parece además que este ritual es, digamos, particular de la isla, frente al de se efectúa en las fiestas en honor a Opis y Arge.

Un grupo y otro de muchachas son de origen hiperbóreo. En el caso de Hipéroca y Laódice su origen queda afianzado además por el hecho de que llegan a la isla portando ofrendas desde su tierra, como después se siguió haciendo, aunque de otro modo, como hemos visto. Heródoto dice que Opis y Arge eran «vírgenes hiperbóreas» ${ }^{105}$, aunque en este caso el asunto no está tan claro como en los anteriores. No hay por qué dudar de Heródoto, y podemos pensar que como Leto, según algún mito ${ }^{106}$, es hiperbórea, estas muchachas vienen desde su tierra a acompañar a su paisana en el parto.

En este asunto de las ofrendas y las muchachas hiperbóreas, creemos que, por más que lo estudiemos, siempre quedan cabos sueltos; con todo, esperamos haber contribuido en algo a aclarar mito y realidad.

\section{BIBLIOGRAFÍA}

BiancuCCI, G.B. (1973), «La via iperborea», RFIC 101, pp. 207-220.

BURKERT, W. (2007), Religión griega arcaica y clásica, Madrid, Abada.

CourBy, F. (1912), Exploration archéologique de Délos V: Le portique d'Antigone, París, École française d'Athènes.

\footnotetext{
${ }^{99}$ Servio, Comentraio a la Eneida, 11.532.

${ }^{100}$ Sale (1961: 79) y Nilsson (1968: 614).

101 (2007: 203).

${ }^{102}$ Que los griegos ya del s.VII a.C. considerarían como muy antiguas.

${ }^{103}$ Himno homérico a Apolo, 146 y ss.

${ }^{104}$ Cuyo nombre tiene que ver con la raíz del verbo *phéro, «llevar». Por tanto son «portadores de algo», con toda seguridad «portadores de ofrendas».

1054.35 .

${ }^{106}$ Grimal (1981: 315).
} 
Courby, F. (1938), «Études d'epigraphie délienne. II Notes sur un compte rendu de gestion Amphiktyonique (IV e.S.)», $B C H$ 62, pp. 85-96.

Desautels, J (1971), «Les monts Riphées el les hyperboréens dans le traité hippocratique des airs, des Eaux et des Lieux», REG 84, pp. 289-296.

Dicks, D.R. (1966), «Solstices, Equinoxes, and the Presocratics», JHS 86, pp. 26- 40.

Drews, R (1976), «The earliest Greek settlements on the Black Sea», JHS 96, pp. 18-31.

Durrbach, F. (1911), «Foullies de Délos, executées aux frais de M. le Duc de Loubat. Inscriptions financières (1906-1919) I», BCH 35, pp. 5-86.

Grimal, P. (1981), Diccionario de mitología griega y romana, Barcelona, Paidós.

HARris, J. R. (1925), «Apollo at the back of the north wind», JHS 45, pp. 229-242.

KAHN, Ch. H. (1970), «On early Greek astronomy», JHS 90, pp. 99-116.

Legrand, Ph. E. (1960), Histoires. Livre 4. Melpomène, París, Les Belles Lettres.

LucAs, J. M. (2008), Esquilo. Testimonios y fragmentos, Madrid, Biblioteca Clásica Gredos.

Merkelbach, R.- West, M. (1990), Fragmenta selecta, Oxford, Oxford Classical Texts.

Mineur, W.H. (1984), Callimacus. Hymn to Delos. Introduction and commentary, Leiden, E. J. Brill.

Navarro, J. M. de (1925), «Prehistoric routes between northern Europe and Italy defined by amber trade», GJ 66, 6, pp.481-503.

NiLsson, M. P. (1968), The Minoan-Mycenean religion and its survival in Greek religion, Lund. Gleerup.

PAGe, D. (1979), Sappho and Alcaeus: an introduction to the study of ancient Lesbian poetry, Oxford, Clarendon Press.

Picard, Ch. - Replat, J. (1924), «Recherches sur la topographie du Hiéron délien», $B C H 48$, pp. 217-263.

PICARD, Ch. (1927), «La Crète et les légendes hyperboréennes», $R A$ 25., pp. 349-360.

- (1946), «La route des processions hyperboréennes en Grèce», RHR 132, pp.98-109.

Pfeiffer, R. (1965), Callimachus. V.2: Hymni et epigrammata, Oxford.

RADT, S. (1985), Tragicorum Graecorum Fragmenta, Gotinga, Vandenhoeck \& Ruprecht.

Romm, J. (1992), The edges of the earth in ancient thought: geography, exploration, and fiction, Princeton, N.J, Princeton University Press.

Rose, Herbert J. (1974), Mitología griega, Barcelona, Labor.

Sale, W. (1961), «The hyperborean maidens on Delos», Harvard theological review, 54, 2 , pp.75-89.

Schrader, C. (1995) (reimpr. 2006), Heródoto. Historia II, Madrid, Biblioteca Clásica Gredos. SEltman, Ch. (1928), «The offerings of the hyperboreans», CQ 22, pp.155-159.

Souvirón, B. (2006), Hijos de Homero: un viaje personal por el alba de occidente, Madrid, Alianza.

- (2008), El rayo y la espada I. Una nueva mirada sobre los mitos griegos, Madrid, Alianza.

- (2011), El rayo y la espada II. Una nueva mirada sobre los mitos griegos, Madrid, Alianza.

TRÉHeux, J. (1953), «La realité des offrandes hyperboréennes», Studies presented to D.M. Robinson II, Washington, pp.758-774. 